\title{
Physical Activity and Healthy Diet in Patients with Familial Hypercholesterolaemia
}

\section{Salmi Razali ${ }^{1,3}$, Yap Bee Wah², Chua Yung An ${ }^{3}$, Hapizah M Nawawi ${ }^{3}$}

1Department of Psychiatry, Faculty of Medicine, UniversitiTeknologi MARA, Malaysia ${ }^{2}$ Faculty of Computer and Mathematical Sciences, UniversitiTeknologi MARA, Malaysia

${ }^{3}$ Institute of Pathology, Laboratory and Forensic Medicine (I-PPerForM)

Faculty of Medicine, UniversitiTeknologi MARA, 47000 Sungai Buloh, Selangor, Malaysia

drsalmi@gmail.com, yapbeewah@salam.uitm.edu.my, yungan.chua@gmail.com, hapizah.nawawi@gmail.com

Tel.: +603-61265000

\begin{abstract}
Performing vigorous physical activity and taking balanced diet are parts of healthy lifestyles of patients with Familial Hypercholesterolaemia (FH). This study aimed to describe the status of engagement with physical activity and a healthy diet, and their contributing factors. FH patients diagnosed using Dutch Lipid Clinic Network criteria were given validated questionnaires to assess sociodemography, illness characteristics, the status of engagement with physical activity and healthy diet, psychological elements, family support and level of barrier. Significant contributing factors were receiving treatment, level of barrier and intention for behavioural change. The findings may inform the strategy for lifestyle modification of patients with $\mathrm{FH}$.
\end{abstract}

Keywords:Familial Hypercholesterolaemia; lifestyle; physical activity; healthy diet

eISSN: 2398-4287@ 2020. The Authors. Published for AMER ABRA cE-Bsby e-International Publishing House, Ltd., UK. This is an open-access article under the CC BYNC-ND license (http://creativecommons.org/licenses/by-ncnd/4.0/). Peer-review under responsibility of AMER (Association of Malaysian Environment-Behaviour Researchers), ABRA (Association of Behavioural Researchers on Asians) and cE-Bs (Centre for Environment-Behaviour Studies), Faculty of Architecture, Planning \& Surveying, Universiti Teknologi MARA, Malaysia.

DOI: https://doi.org/10.21834/jabs.v5i17.374 


\subsection{Introduction}

Cardiovascular diseases (CVDs) is the leading causes of morbidity and mortality worldwide and Familial Hypercholesterolemia (FH) is one of the important risk factors. Globally, one in every 500 to 200 people may have FH. In Malaysia, recent National Health and Morbidity Survey (2019) indicated that hypercholesterolemia is one of the significant risks for cardiovascular disease. The prevalence of hypercholesterolemia is 38.1\%; indicating one in three Malaysians may have this condition (National Institute of Health, Malaysia ,2020). Other major risk factors are diabetes mellitus, obesity and hypertension. FH is an essential cause of hypercholesterolemia among the Malaysian population. In a recent study among the local community, of the total 4821 participants, 9.1\% had severe hypercholesterolemia and the ratio of $\mathrm{FH}$ was estimated to be 1:95; which is more common than most that have been reported in European countries (Razman, et al., 2019).

\subsection{Literature Review}

There are various causes of hypercholesterolaemia; one of the central causes is primary hypercholesterolaemia, including $\mathrm{FH}$. It is primary dyslipidaemia which involved a genetic mutation in cellular transportation and catabolism of LDL-C, such as LDL-receptor (LDLR), apolipoprotein B (APOB), proprotein convertase subtilisin/kexin type 9 (PCSK9) and lowdensity lipoprotein receptor adaptor protein 1 genes (LDLRAP1) (Al-Khateeb et al., 2016). Secondary dyslipidaemia may also cause hypercholesterolemia, but it is often associated with the increase in LDL-C which most often caused by external factors including taking high-fat diet, lack of physical activity and exercise leading to obesity, smoking or, from other diseases such as hypothyroidism, liver disease or chronic renal failure (Al-Khateeb et al., 2016).

Correct diagnosis of Familial Hypercholesterolemia is crucial for effective intervention. Currently, there are a few acceptable criteria used by clinicians worldwide including the Dutch Lipid Clinic Network (DLCN) criteria, Simon Broome (SB) Register, Make Early DiagnosisPrevent Early Death, American Heart Association (US MEDPED), Canadian Simplified Definition, and the Japanese FH Management Criteria, Japanese Atherosclerotic Society(JFHMC) (Suraya et al., 2019, Kramer et al., 2019). The most widely used and common preference for Malaysian clinicians is the DLCN criteria. Points are assigned for family history of hyperlipidaemia or heart disease, clinical characteristics such as tendinous xanthomata, elevated LDL cholesterol, and/or an identified mutation. The cumulative score indicates the status of either score of "definite", "probable", "possible" or "unlikely" to have FH (Austin et al., 2004; Haase and Goldberg, 2012; Nordestgaard et al., 2013). Refer to Table 1 for the complete criteria.

Table 1: The Dutch Lipid Clinic Network Criteria for the Diagnosisof Familial Hypercholesterolemia

\begin{tabular}{|c|c|c|}
\hline Criteria & & Points \\
\hline Family History & $\begin{array}{l}\text { First-degree relative with known premature* coronary and vascular } \\
\text { disease OR } \\
\text { First-degree relative with known LDL-C level above the } 95 \text { th } \\
\text { percentile. }\end{array}$ & 1 \\
\hline
\end{tabular}




\begin{tabular}{|c|c|c|}
\hline & $\begin{array}{l}\text { First-degree relative with tendinous xanthomata and/or arcus } \\
\text { cornealis OR } \\
\text { Children aged less than } 18 \text { years with LDL-C level above the 95th } \\
\text { percentile. }\end{array}$ & 2 \\
\hline \multirow[t]{2}{*}{ Clinical History } & Patient with premature* coronary artery disease. & 2 \\
\hline & Patient with premature* cerebral or peripheral vascular disease. & 1 \\
\hline \multirow[t]{2}{*}{ Physical Examination } & Tendinous xanthomata & 6 \\
\hline & Arcus cornealis prior to age 45 years. & 4 \\
\hline \multirow{4}{*}{$\begin{array}{l}\text { Cholesterol levels } \mathrm{mg} / \mathrm{dl} \\
\text { (mmol/liter) }\end{array}$} & $\mathrm{LDL}-\mathrm{C}>=330 \mathrm{mg} / \mathrm{dL}(\geq 8.5)$ & 8 \\
\hline & LDL-C $250-329 \mathrm{mg} / \mathrm{dL}(6.5-8.4)$ & 5 \\
\hline & LDL-C $190-249 \mathrm{mg} / \mathrm{dL}(5.0-6.4)$ & 3 \\
\hline & LDL-C $155-189 \mathrm{mg} / \mathrm{dL}(4.0-4.9)$ & 1 \\
\hline DNA Analysis & Functional mutation in the LDLR, apo B or PCSK9 gene & 8 \\
\hline \multirow{4}{*}{$\begin{array}{l}\text { Diagnosis (diagnosis is } \\
\text { based on the total } \\
\text { number of points } \\
\text { obtained) }\end{array}$} & Definite familial hypercholesterolemia & $>8$ \\
\hline & Probable familial hypercholesterolemia & $6-8$ \\
\hline & Possible familial hypercholesterolemia & $3-5$ \\
\hline & Unlikely familial hypercholesterolemia & $<3$ \\
\hline \multicolumn{3}{|c|}{$\begin{array}{l}\text { *Premature }=<55 \text { years in men; }<60 \text { years in women } \\
\text { LDL-C = low density lipoprotein cholesterol; FH, familial hypercholesterolemia. } \\
\text { LDLR = low density lipoprotein receptor } \\
\text { Apo B = apolipoprotein B } \\
\text { PCSK9 = Proprotein convertase subtilisin/kexin type } 9\end{array}$} \\
\hline
\end{tabular}

Source: This table is adapted from Austin et al., 2004; Haase and Goldberg, 2012; Nordestgaard et al., 2013.

FH causes various severe CVDs and other complications, and if untreated. Patients with $\mathrm{FH}$ will suffer reduced life expectancy by up to 30 years compared those without FH (Alonso, Mata, \& Mata, 2005). Without early treatment, CVDs and other complications caused patients with FH to have a poor quality of life (Razali, Ismail, Yung et al., 2019). Hence, preventive measures of CVDs including taking lipid-lowering agents, stress management and lifestyle interventions (such as taking healthy diet, performing vigorous physical activities, exercise and smoking cessation) are vital. Moreover, positive illness perceptions and belief on the illness is crucial for adherence to treatment and early preventive measures (Razali, Ismail, \& Abdullah et al., 2019).

In order to ensure life-long behavioural modification, the underlying health-related psychological process that shapes the intention for behavioural changes must well be understood to inform effective interventions (Hagger et al., 2016). These underlying psychological processes in behavioural change has been explained by many theories (Bandura, 1986; Prochaska, 1998; Ajzen, 1985). One of the popular theories is the Theory of Planned Behaviour (TPB) which was introduced by IcekAjzen in 1985 and further elaborated in 2011 (Refer Figure 1). 


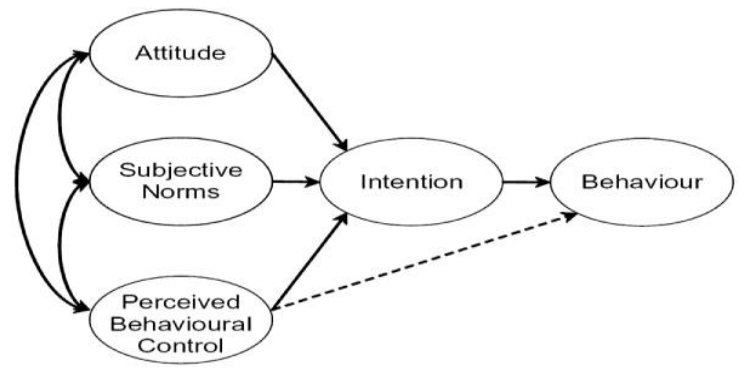

Figure 1: Theory of Planned Behaviour

Source: The diagram is adapted from IcekAjzen (2011)

The theory suggested that a 'behaviour' is dependent on one's 'intention' to perform the behaviour (i.e. engagement with physical activity and healthy diet) and the 'intention' is dependent on the 'attitude' (beliefs and values about the outcome of the behaviour), 'subjective norms' (beliefs about what other people think the person should do or general social pressure) and 'perceived behavioural control' or one's perceptions of his ability or feelings of self-efficacy to perform the behaviour (Ajzen, 1985, 2011). Some of the examples of the 'attitude' for engagement with physical activity and healthy diet include perceptions that practising these lifestyles is vital for the prevention of cardiovascular complications, performing exercise and taking a healthy diet is essential for having appropriate body weight or many others. Examples of 'subjective norms' include common practices of unhealthy diet during festivals, poor diet control when going out together with friends and many others. As part of the general social pressure, experts in behaviour also believe that support and barriers from surrounding social elements may influence patients' decision to perform the behaviour.

To date, there is still sparse knowledge and awareness of the psychological concepts that contribute to the lifestyles of patients with $\mathrm{FH}$ among both the public and patients. Hence, this study aimed to i) describe the lifestyle of patients with $\mathrm{FH}$ (including engagement with physical activity and taking healthy diet) and, ii) determine the associations between the lifestyles and sociodemographic factors, illness characteristics, the underlying health-related psychological elements (including intention, attitude, subjective norms and perceived behavioural control), family support and level of barrier.

\subsection{Methodology}

This study was a cross-sectional study which used convenient sampling for recruitment. The study was conducted at the Specialist Lipid and Coronary Risk Prevention Clinics in a Teaching Hospital in Malaysia. The selection criteria include participants aged 18 years or more who were patients diagnosed with FH according to Dutch Lipid Clinic (DLC) criteria. Prior to the commencement of the study, written informed consent was granted from all participants.

Self-reported pro forma questionnaires were used to assess sociodemographic 
background, illness characteristics, family support and barrier for performing physical activity and taking healthy diet. Sociodemographic variables include information regarding gender, age, marital status, level of education and their total household income per month. Illness characteristics include the presence of CVDs, type of CVDs (including coronary heart disease, angina, stroke atherosclerosis and peripheral vascular disease) treatment for $\mathrm{FH}$, and risk factors for coronary artery disease (including smoking status, high blood pressure, depression and high stress). The underlying health-related psychological concepts (such as intention, attitude, subjective norms, perceived behavioural control) were assessed using questionnaires constructed based on the TPB (Ajzen, 2011).

Statistical Package for the Social Sciences version 24 was used to analyse the data. Data were mostly recategorised into dichotomous data. The associations between sociodemographic factors, illness characteristics, domains of TPB (attitude, subjective norms, perceived behavioural control and intention), family support and level of barrier and domains of lifestyles (engagement with physical activity and taking healthy diet) were analysed using Chi-Square analysis. Multiple regressions were carried out to identify the determinants of engagement with physical activity and taking healthy diet. The study was approved by the Institutional Research Ethics committee (600-RMI (5/1/6).

\subsection{Results}

\subsection{Background Sociodemography}

A total of hundred participants (37\% male and $63 \%$ female), predominantly in the late forties (mean \pm SD: $49.8 \pm 11.4$ years old) and ever-married individuals $(92 \%)$ participated in the study. They were mainly from a lower socioeconomic position with which $55 \%$ of the participants had a total household income less than RM3000 a month, and $52 \%$ of studied participants attained only up to the level of secondary education.

\subsection{IIIness Characteristics}

Less than half ( $41 \%)$ of the patients with FH had CVDs; mainly coronary heart disease ( $n=35$; $85.4 \%)$, angina $(n=8 ; 19.5 \%)$, atherosclerosis $(n=4 ; 9.8 \%)$, stroke $(n=4 ; 9.8 \%)$ and one participant had peripheral arterial disease. About two-thirds (69\%) of the participants received lipid-lowering agents. More than a third (40\%) of the participants had hypertension, $13 \%$ were smokers, and $8 \%$ reported feeling stressed up and complained of feeling depressed.

\subsection{Lifestyle Pattern}

The majority 66(68.8\%) of Patients with FH in the study reported that they had been taking healthy diet. However, less than half of the patients reported that they engaged with physical activity (Figure 2). Only 13 (13\%) of Patients with FH in the study were still smoking during the study period. 


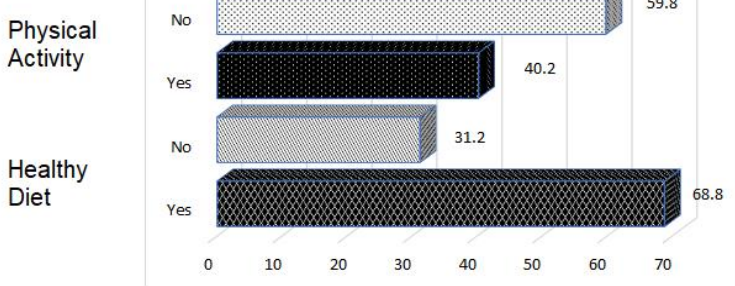

Percentage

Figure 2. Percentages of the Lifestyles (Engagement in Physical Activity and Healthy Diet)

\subsection{Family Support and Level of Barrier}

Most of the respondents $(63 ; 63 \%)$ did not have the barriers to perform the physical activity, $14(14 \%)$ of respondents complained that time factor as their barrier to perform physical activity, $7(7 \%)$ of respondents mentioned that health problem as their barrier and the others described of being lazy, busy with work and bad weathers as their barriers to performing physical activity. In terms of taking healthy diet, most of the respondents, 76(76\%) did not have the barriers to take healthy diet, $10(10 \%)$ of respondents complained of difficulty to control their appetite as their barrier to take healthy diet and others complained that having friends, family, and attending ceremony and availability of unhealthy food as their barrier to taking healthy diet. For family support, of the total, about $81.8 \%$ and $89.5 \%$ of respondents had family support to perform physical activity and taking health diet respectively.

\subsection{Contributing Factors for Engagement with Physical Activities}

There were significant associations between the engagement with physical activities, and the status of receiving treatment, the intention to perform the physical activity and the level of barrier. Patients with $\mathrm{FH}$ engaged in physical activity were significantly higher $\left(\mathrm{X}^{2}(1)=4.895\right.$; $p=0.027)$ among those who were receiving treatment $(n=22 ; 56.4 \%)$ than those who were not $\left(n=17(43.6 \%)\right.$. Those who engaged in physical activity were also significantly higher $\left(X^{2}(1)\right.$ $=11.379 ; p=0.001 ;$ Yates correction: $X^{2}(1)=9.734 ; p=0.002$ ) among Patients with $F H$ who had intention $(n=37 ; 68.3 \%)$ than those who had no intention to perform the physical activity $(n=18(32.7 \%)$. Moreover, in terms of the level of barrier, the patients engaged in physical activity were significantly higher $\left(X^{2}(1)=15.303 ; \quad p=0.000 ;\right.$ Yates correction: $\left(X^{2}\right.$ $(1)=13.663 ; p=0.000)$ among those who had a low level of barrier $(n=34 ; 87.2 \%)$ than those who had a high level of barrier $(n=5 ; 12.8 \%)$ (Refer to Table 2 ).

Multiple logistic regressions were performed to identify the determinants for engagement with physical activity. The independent variables included in the model development were gender, age, total household income, presence of CVD, the status of receiving treatment, intention, family support and the level of barrier. The Omnibus test for model coefficient showed that the model was significant $\left(X^{2}(8)=34.929 ; p<0.001\right.$; the Nagelkerke $R^{2}=0.413$; 
Cox \& Snell $R^{2}=0.305$ ) and the predictive accuracy of the model for the training sample was $78.10 \%$. There was no multicollinearity exist between independent variables; the values for tolerance were more than 0.1 , and VIF was less than 10 for each variable. The significant determinants for engagement of physical activity of the Patients with $\mathrm{FH}$ were the intention to perform $(B=2.213 ; A O R=9.145 ; p=0.020)$ and the level of barrier $(B=-1.892 ; A O R=0.151$; $p=0.002)$.

Table 2: Engagement with Physical Activity and Possible Contributing Factors

\begin{tabular}{|c|c|c|}
\hline \multirow{2}{*}{ Variable: } & \multicolumn{2}{|c|}{ Physical activity } \\
\hline & Yes & No \\
\hline \multicolumn{3}{|l|}{ Sociodemography } \\
\hline Age & $38(49.5 \pm 13.2)$ & $58(49.9 \pm 9.3)$ \\
\hline \multicolumn{3}{|l|}{ Gender } \\
\hline Female & $12(30.8 \%)$ & $24(41.4 \%)$ \\
\hline Male & $27(69.2 \%)$ & $34(58.6 \%)$ \\
\hline \multicolumn{3}{|l|}{ Marital status } \\
\hline Ever married & $35(89.7 \%)$ & $55(94.8 \%)$ \\
\hline Unmarried & $4(10.3 \%)$ & $3(5.2 \%)$ \\
\hline \multicolumn{3}{|l|}{ Education } \\
\hline Pre-university and university & $34(61.8 \%)$ & $11(26.8 \%)$ \\
\hline Secondary & $17(30.9 \%)$ & $27(65.9 \%)$ \\
\hline Primary and below & $4(7.3 \%)$ & $3(7.3 \%)$ \\
\hline \multicolumn{3}{|l|}{ Income (RM) } \\
\hline$<3000$ & $21(53.8 \%)$ & $32(55.2 \%)$ \\
\hline $3001-10000$ & $17(43.6 \%)$ & $18(32.1 \%)$ \\
\hline$>10000$ & $1(2.6 \%)$ & $8(13.8 \%)$ \\
\hline \multicolumn{3}{|l|}{ IIIness Characteristics } \\
\hline \multicolumn{3}{|l|}{ CVD } \\
\hline Presence & $15(87.2 \%)$ & $26(44.8 \%)$ \\
\hline Absent & $24(12.8 \%)$ & $32(55.2 \%)$ \\
\hline \multicolumn{3}{|l|}{ Receiving FH Treatment * } \\
\hline Yes & $22(56.4 \%)$ & $45(77.5 \%)$ \\
\hline No & $17(43.6 \%)$ & $13(22.4 \%)$ \\
\hline \multicolumn{3}{|l|}{ Comorbidity } \\
\hline Single & $14(93.3 \%)$ & $20(71.4 \%)$ \\
\hline Presence & $1(6.7 \%)$ & $8(28.6 \%)$ \\
\hline \multicolumn{3}{|l|}{ Risk Factors } \\
\hline Single & $17(85,0 \%)$ & $23(71.9 \%)$ \\
\hline Multiple & $3(15.0 \%)$ & $9(2.8 \%)$ \\
\hline \multicolumn{3}{|c|}{ Psychological element in the Theory of Planned Behaviour } \\
\hline \multicolumn{3}{|c|}{ Subjective norms } \\
\hline Yes & $38(97.4 \%)$ & $55(96.5 \%)$ \\
\hline No & $1(0.6 \%)$ & $2(3.5 \%)$ \\
\hline \multicolumn{3}{|l|}{ Perceived behavioural control } \\
\hline Yes & $37(94.9 \%)$ & $55(98.2 \%)$ \\
\hline No & $2(5.1 \%)$ & $1(1.8 \%)$ \\
\hline \multicolumn{3}{|l|}{ Attitude } \\
\hline Good & $39(100.0 \%)$ & $56(96.6 \%)$ \\
\hline Bad & $0(0 \%)$ & $2(3.4 \%)$ \\
\hline Excited & $39(100.0 \%)$ & $55(58.5 \%)$ \\
\hline Boring & $0(0 \%)$ & $3(100 \%)$ \\
\hline
\end{tabular}




\begin{tabular}{lcc} 
Fun & $39(100.0 \%)$ & $53(94.8 \%)$ \\
Unpleasant & $0(0.0 \%)$ & $5(5.2 \%)$ \\
Intention $^{* *}$ & & \\
Yes & $37(68.3 \%)$ & $40(95.2 \%)$ \\
No & $18(32.7 \%)$ & $2(4.7 \%)$ \\
\hline Family Support & & \\
\hline Yes & $35(89.7 \%)$ & $45(77.6 \%)$ \\
No & $4(10.3 \%)$ & $13(22.4 \%)$ \\
\hline Level of Barrier** & & \\
\hline Low & $34(87.2 \%)$ & $28(48.3 \%)$ \\
High & $5(12.8 \%)$ & $30(51.7 \%)$ \\
\hline
\end{tabular}

Chi-square tests were used in the analyses of associations between engagement with physical activity and the possible determinants except for age. Yates corrections were performed when the cell frequency was less than 10. * $p$-value $<0.05$.; ${ }^{* *} p$-value $<0.01$.

\subsection{Contributing Factors for Taking Healthy Diet}

There were significant associations between taking healthy diet and the status of receiving treatment and the level of barrier. Patients with $\mathrm{FH}$ taking healthy diet were significantly higher $(X 2(1)=8.107 ; p=0.004)$ among those who were receiving treatment $(n=57 ; 78.8 \%)$ than those who were not $(n=14 ; 21.2 \%)$. Those who were taking healthy diet were also significantly higher $\left(X^{2}(1)=7.822 ; p=0.005\right.$; Yates correction: $\left(X^{2}(1)=6.465 ; p=0.011\right)$ among Patients with $\mathrm{FH}$ who had low level of barrier $(n=55 ; 83.3 \%)$ than those who had high level of barrier $(n=11 ; 16.7 \%)$. Refer to Table 3 for further details.

In the model development, we included gender, age, total household income, presence of CVD, the status of receiving treatment, and level of barrier in the analysis. The Omnibus test for model coefficient showed that the model was significant $\left(X^{2}(6)=19.086 ; p<0.001\right.$; the NagelkerkeR ${ }^{2}=0.257$; Cox \& Snell $R^{2}=0.182$ ) and the predictive accuracy of the model for the training sample was $75.80 \%$. There was no multicollinearity exist between independent variables; the values for tolerance were more than 0.1 , and VIF was less than 10 for each variable. The significant determinants for taking healthy diet in Patients with $\mathrm{FH}$ were the status of receiving treatment $(B=1.376 ; A O R=3.961 ; p=0.024)$ and the level of barrier $(B=-$ 1.650; $A O R=0.192 ; p=0.003)$.

Table 3: Status of Taking Healthy Diet and Possible Contributing Factors

\begin{tabular}{lcc}
\multicolumn{1}{c}{ Variables } & Yes & No \\
\hline Sociodemography & & \\
\hline Age & $38(49.5 \pm 13.2)$ & $58(49.9 \pm 9.3)$ \\
Gender & & \\
$\quad$ Female & $12(30.8 \%)$ & $24(41.4 \%)$ \\
$\quad$ Male & $27(69.2 \%)$ & $34(58.6 \%)$ \\
Marital status & & \\
$\quad$ Ever married & $35(89.7 \%)$ & $55(94.8 \%)$ \\
$\quad$ Unmarried & $4(10.3 \%)$ & $3(51.7 \%)$ \\
Education & & \\
$\quad$ Pre-university and university & $34(61.8 \%)$ & $11(26.8 \%)$
\end{tabular}




\begin{tabular}{|c|c|c|}
\hline Secondary & $17(30.9 \%)$ & $27(65.9 \%)$ \\
\hline Primary and below & $4(7.3 \%)$ & $3(7.3 \%)$ \\
\hline \multicolumn{3}{|l|}{ Income (RM) } \\
\hline$<3000$ & $21(53.8 \%)$ & $32(55.2 \%)$ \\
\hline $3001-10000$ & $17(43.6 \%)$ & $18(31.0 \%)$ \\
\hline$>10000$ & $1(2.6 \%)$ & $8(13.8 \%)$ \\
\hline \multicolumn{3}{|l|}{ Illness Characteristics } \\
\hline \multicolumn{3}{|l|}{ CVD } \\
\hline Presence & $31(47.0 \%)$ & $10(33.3 \%)$ \\
\hline Absent & $35(53.0 \%)$ & $20(66.7 \%)$ \\
\hline \multicolumn{3}{|c|}{ Receiving FH Treatment * } \\
\hline Yes & $52(78.8 \%)$ & $15(50.0 \%)$ \\
\hline No & $14(21.2 \%)$ & $15(50.0 \%)$ \\
\hline \multicolumn{3}{|l|}{ Comorbidity } \\
\hline Single & $26(81.3 \%)$ & $8(72.7 \%)$ \\
\hline Presence & $6(18.7 \%)$ & $3(27.3 \%)$ \\
\hline \multicolumn{3}{|l|}{ Risk Factors } \\
\hline Single & $31(77.5 \%)$ & $9(75.0 \%)$ \\
\hline Multiple & $9(2.25 \%)$ & $3(25.0 \%)$ \\
\hline \multicolumn{3}{|c|}{ Psychological element in the Theory of Planned Behaviour } \\
\hline \multicolumn{3}{|c|}{ Subjective norms } \\
\hline Yes & $64(97.0 \%)$ & $28(96.6 \%)$ \\
\hline No & $2(3.0 \%)$ & $1(3.4 \%)$ \\
\hline \multicolumn{3}{|c|}{ Perceived behavioural control } \\
\hline Yes & $64(97.0 \%)$ & $28(93.3 \%)$ \\
\hline No & $2(3.0 \%)$ & $2(6.7 \%)$ \\
\hline \multicolumn{3}{|l|}{ Attitude } \\
\hline Good & $66(71.7 \%)$ & $26(86.7 \%)$ \\
\hline Bad & $0(0 \%)$ & $4(13.3 \%)$ \\
\hline Excited & $64(98.5 \%)$ & $25(83.3 .1 \%)$ \\
\hline Boring & $1(1.5 \%)$ & $5(16.7 \%)$ \\
\hline Fun & $62(96.8 \%)$ & $24(80.0 \%)$ \\
\hline Unpleasant & $2(3.1 \%)$ & $6(20.0 \%)$ \\
\hline \multicolumn{3}{|l|}{ Intention } \\
\hline Yes & $64(97.0 \%)$ & $22(73.3 \%)$ \\
\hline No & $2(3.0 \%)$ & $8(26,7 \%)$ \\
\hline \multicolumn{3}{|l|}{ Family Support } \\
\hline Yes & $62(94.0 \%)$ & $23(79.3 \%)$ \\
\hline No & $4(6.0 \%)$ & $6(20.6 \%)$ \\
\hline \multicolumn{3}{|l|}{ Level of Barrie*** } \\
\hline Low & $55(83.3 \%)$ & $17(56.7 \%)$ \\
\hline High & $11(16.7 \%)$ & $13(43.3 \%)$ \\
\hline
\end{tabular}

Chi-square tests were used in the analyses of associations between taking healthy diet and the possible determinants except for age. Yates corrections were performed when the cell frequency was less than $10 .{ }^{*} p$-value $<0.05$.; ${ }^{* *} p$-value $<0.01$.

\subsection{Discussion}

This study highlighted the possible factors that influence the lifestyles of patients with $\mathrm{FH}$ is essential to inform clinicians of further interventions for their patients. In our study, barriers prevented our patients with FH from performing healthy lifestyles. Though about two-thirds 
did not describe any difficulties in performing physical activity or taking healthy diet, other participants in our study complained of external factors (such as bad weathers, friends and family problems) as parts of the hurdles. They also described internal factors (such as being lazy, poor time management, poor self-control) played as important hurdles for healthy lifestyles. These findings were supported by other researchers which indicated that, in terms of physical activity and managing weight problem, the main barriers in performing exercise and physical activity include lack of family and friend's involvement, poor weather, lack of discipline and suitable time as well as a financial problem (Ibrahim et al., 2013). For healthy diet intake, factors such as time, food taste and price were suggested to be the main challenges to comply towards dietary counselling (Sulaiman et al., 2016). Hence, it is critical to minimise barriers to ensure that patients with $\mathrm{FH}$ maintain their lifestyle behaviour and modification.

In a study examining the barriers experienced by patients with hyperlipidaemia, a group of health providers have divided the barriers into; i) provider barriers (including poor tracking and patient follow-up, poor understanding of guidelines and the literature, controversy over guideline recommendations, poor understanding of patient needs, and inadequate training in facilitating behavioural change in patients); ii) patient barriers (including poor adherence to referrals, asymptomatic nature of the diseases, linguistic and cultural difficulties, psychosocial challenges blunting efforts to adhere, poor patient's acceptance of the disease, and difficulty of lifestyle changes); and iii) practice/system barriers (including poor multidisciplinary cooperation, documentation burdens, difficulty educating patients at the right educational level, and difficulty coordinating care with the hospital) (Cook et al., 2006). Addressing all these barriers is crucial for the comprehensive management of patients with $\mathrm{FH}$.

Previous experts in psychology have suggested through their proposed theory of the associations between intention and lifestyle behaviour (Fishbein, 1980; Fishbein\&Ajzen, 1975; Ajzen, 1985, 1991; Triandis, 1980; Rogers, 1983). Our study supported this link and suggested that patients with $\mathrm{FH}$ should have sturdy intention in order to perform physical activities. In other study investigating lifestyle of patients with $\mathrm{FH}$ using the integrated psychological model, Hagger and colleagues (2016) have demonstrated that not only the intention but also attitude plays as an essential mediator for lifestyle changes in patients with $\mathrm{FH}$. Given the importance of intention in behavioural modification strategy, clinicians in particular health psychologist should enhance patients with $\mathrm{FH}$ understanding of this psychological element when providing counselling on the self-management support service for patients with $\mathrm{FH}$.

We also found that the lifestyle of our patients with $\mathrm{FH}$ associates to their illness condition, i.e. their status of receiving treatment. It is easy to assume that those patients with $\mathrm{FH}$ who were receiving treatment were among those who have good insight and awareness of the needs for treatment (Eriksson et al., 2006). Perhaps, the intermediating factor is the anxiety of having the consequences may motivate Patients with $\mathrm{FH}$ who were receiving treatment to have an improved lifestyle. Patients with FH who received treatment may have continuous counselling on the need for healthy lifestyle every time they visit the clinic for regular 
consultations. It is crucial for clinicians to provide counselling on both adherence to medications and a healthy lifestyle as part of the intervention for patients with $\mathrm{FH}$.

The results of this study also supported and added to other determinants that were found by other researchers who examined the lifestyle of general populations (Chan et al., 2015; Cheah\&Poh, 2014). In their studies, other factors contributing to lifestyles include age, income, gender, education, marital status, region, house locality, job characteristics, and medical conditions have been suggested (Cheah\&Poh, 2014). In order to ensure patients with $\mathrm{FH}$ have the optimum quality of life, apart from practising health lifestyle, Patients with $\mathrm{FH}$ should also have equipped themselves with positive perceptions and enough knowledge on the illness itself and its complications (Razali et al., 2019).

\subsection{Conclusion and Recommendations}

We highlighted that patients with $\mathrm{FH}$ who engaged with physical activity are those who are receiving treatment, experiencing a low level of barrier and have the intention to perform physical activities. Patients who are receiving treatment and experiencing a low level of barrier are also more likely to take a healthy diet. $\mathrm{FH}$. It is crucial to minimise the barriers and enhance the counselling that instilling psychological resilience, in particular, increasing the intention of performing healthy lifestyles. Further in-depth studies to understand both these elements are crucial. Clinicians should be aware of these elements to ensure effective advice for lifestyle modification of patients with FH. Nonetheless, the results should be interpreted with care because this study is limited with a small sample size, and we used self-perception in describing the level of engagement with physical activities and taking healthy diet. Furthermore, there are many other cultural beliefs and perceptions that may not be captured by the questionnaires that may influence the lifestyles of patients with $\mathrm{FH}$. In future, more improvement in the study methods is required for more impactful findings.

\section{Acknowledgement}

This study was funded by UiTM MITRA Grant [grant code: 600-IRMI/MYRA 5/3/MITRA (003/2017)-2)] awarded to the first and corresponding authors. The findings of this study were also presented and published in the proceeding paper of the AMEABRA International Virtual Conference on Environment-Behaviour Studies, 1st Series, UniversitiTeknologi MARA, Shah Alam, 24 Jun 2020.

\section{References}

Austin M.A., Hutter C.M., Zimmern R.L., Humphries S.E. (2004) Genetic causes of monogenic heterozygous familial hypercholesterolemia: a HuGE prevalence review. American journal of epidemiology.160:407-420.

Ajzen, Icek (2011). The theory of planned behaviour: Reactions and reflections. Journal Psychology \& Health; 26(9); 1113-1127 
Al-Khateeb, A., Hamzan, N.S., Razali, R., Froemming, GA., Rahman, T., Peng, H.B., \&Nawawi, H. (2016). Genetic Study of Low-Density Lipoprotein Receptor Gene and Apolipoprotein B-100 Gene among Malaysian Patients with Familial Hypercholesterolaemia. International Archives of Medicine, 9.

Alonso, R., Mata, N., \& Mata, P. (2005). Benefits and risks assessment of simvastatin in familial hypercholesterolaemia. Expert Opinion on Drug Safety, 4(2), 171-181.

Bandura, A. (1986). Social Foundations of Thought and Action. Englewood Cliffs, New Jersey: Prentice-Hall.

Chan, Y., Teh, Ch., Lim, K.K., Lim, K.H., Yeo, PS., Kee, C.C., Omar, M.A and Ahmad, N.A (2015). Lifestyle, chronic diseases and self-rated health among Malaysian adults: results from the 2011 National Health and Morbidity Survey; BMC Public Health, 15:754

Cheah, Y.K. and Poh, B.K. (2014).The Determinants of Participation in Physical Activity in Malaysia; Osong Public Health and Research Perspectives; 5(1);20-27

Cook, S., Drum, M.L., Kirchhoff, A.C., Jin, L., Levie, J., Harrison, J.F., ... Chin, M.H. (2006). Providers' Assessment of Barriers to Effective Management of Hypertension and Hyperlipidemia in Community Health Centers. Journal of Health Care for the Poor and Underserved 17(1), 70-85. doi:10.1353/hpu.2006.0021.

Eriksson, K.M., Westborg, C.J. Mats CE, and Eliasson (2006) A randomised trial of lifestyle intervention in primary healthcare for the modification of cardiovascular risk factors The Björknäs study. Scandinavian Journal of Public Health, 34 (5)

Fishbein, M., \&Ajzen, I. (1975). Belief, Attitude, Intention and Behavior: An Introduction to Theory and Research. Reading, MA: Addison-Wesley.

Fishbein, M. (1980). A theory of reasoned action: Some applications and implications. In H. Howe \& M. Page (Eds.), Nebraska Symposium on Motivation (Vol. 27, pp. 65- 116). Lincoln, NB: University of Nebraska Press.

Haase A, Goldberg A.C. (2012). Identi cation of people with heterozygous familial hypercholesterolemia. Current opinion in lipidology. 23:282-289.

Hagger, M.S., Hardcastle, S.J., Hingley, C., Strickland, E., Pang, J., \& Watts, G.F. (2016). Predicting selfmanagement behaviours in familial hypercholesterolaemia using an integrated theoretical model: The impact of beliefs about illnesses and beliefs about behaviours. International Journal of Behavioral Medicine, 23(3), 282-294.

Ibrahim, S., Karim, N.A., Oon, NL, and Wan Ngah, W.Z. (2013) Perceived physical activity barriers related to body weight status and sociodemographic factors among Malaysian men in Klang Valley; BMC Public Health.13:275

Kramer, A.I., Trinder, M., and Brunham, L.R. (2019), Estimating the Prevalence of Familial Hypercholesterolemia in Acute Coronary Syndrome: A Systematic Review and Meta-analysis; Canadian Journal of Cardiology; 35(10),13221331

National Institute of Health, Malaysia (2020), National Health and Morbidity Survey (2019). Factsheet: Noncommunicable Diseases Healthcare Demand and Health Literacy. Retrieved from http://www.iku.gov.my/images/IKU/Document/REPORT/NHMS2019/Fact_Sheet_NHMS_2019-English.pdf.

Nordestgaard B.G., Chapman M.J., Humphries S.E,, et al. (2013). Familial hypercholesterolaemia is underdiagnosed and undertreated in the general population: guidance for clinicians to prevent coronary heart disease: consensus statement of the European Atherosclerosis Society. European Heart Journal.34:3478-3490a. 
Prochaska, J., Johnson, S., \& Lee, P. (1998). The transtheoretical model of behaviour change. In S. Schumaker, E. Schron, J. Ockene\& W. McBee (Eds.), The Handbook of Health Behavior Change, 2nd ed. New York, NY: Springer.

Razali, S., Ismail, Z., Abdullah, N., and Nawawi, H.M (2019). Illness Perception of Patients with Familial Hypercholesterolaemia varies with Level of Education and Presence of Cardiovascular Disease; EnvironmentBehaviour Proceedings Journal; 4(10);72-78. DOI: https://doi.org/10.21834/e-bpj.v4i10.1620

Razali, S., Ismail, Z., Yung, A.C., and Nawawi, H.M (2019). Quality of Life and Its Contributing Factors in Patients with Familial Hypercholesterolaemia in Malaysia; Environment-Behaviour Proceedings Journal; 4(10); 86-92. DOI: https://doi.org/10.21834/e-bpj.v4i10.1621

Razman, Z., Chua, Y.A., MohdKassim, N.A.,Mohd Nor, N.S., Razak, S., Ramli, A.S., MohdNawawi, H. (2019) Familial Hypercholesterolaemia In Malaysian Community Is More Common Than That In Most European Countries, I Atherosclerosis 287 (2019) e123ee288

Rogers, R. W. (1983). Cognitive and physiological processes in fear appeals and attitude change: A revised theory of protection motivation. In B. L. Cacioppo \& L. L. Petty (Eds), Social Psychophysiology: A Sourcebook. London: Guilford

Cook, S., Drum, M.L., Anne C. Kirchhoff, A.C., Jin, L., Levie, J., Harrison, J.F., Lippold, S.A., Schaefer, C.T., Chin, M.H.(2006), Providers' Assessment of Barriers to Effective Management of Hypertension and Hyperlipidemia in Community Health Centers, Journal of Health Care for the Poor and Underserved, 17(1).

Sulaiman, S., Abdul Manaf, Z and Shahril M.R. (2016) Compliance to Dietary Counselling in Controlling Blood Lipid and its Barriers among Dyslipidemic Individuals. Journal on Advanced Science, Engineering and Information Technology 6 (5)

Triandis, H. C. (1980). Values, attitudes, and interpersonal behaviour. In H. Howe \& M. Page (Eds), Nebraska Symposium on Motivation (Vol. 27, pp. 195-259). Lincoln, NB: University of Nebraska Press.

Ying Vallejo-Vaz, A.J., De Marco, M., Stevens, C.A.T., Akram, A., Freiberger, T., Hovingh, G.K., et al. (2018). Overview of the current status of familial hypercholesterolaemia care in over 60 countries - The EAS Familial Hypercholesterolaemia Studies Collaboration (FHSC). Atherosclerosis, 277, 234-255. 